\title{
(i) TITLE
}

\section{Acceptability of the culturally adapted ASQ-TRAK developmental screening tool to caregivers of Aboriginal children}

\section{(ii) TYPE OF MANUSCRIPT}

Original Article

\section{(iii) AUTHORS}

Kimberly Johansen ${ }^{1}$

Deepa Jeyaseelan ${ }^{1,2}$

Yee Pei Chan ${ }^{1}$

Samantha Simpson ${ }^{3}$

Maree O'Keefe ${ }^{2,4}$

Anita D’Aprano 3, 5, 6

\section{(iv) INSTITUTIONS}

1 Women's and Children's Health Network, Adelaide, South Australia, Australia.

2 Child Development Unit, Women's and Children's Health Network, Adelaide, South Australia, Australia.

3 Melbourne Graduate School of Education, University of Melbourne, Victoria, Australia. 4 Faculty of Health and Medical Sciences, University of Adelaide, South Australia, Australia. 5 Department of Paediatrics, University of Melbourne, Victoria, Australia.

6 Population Health Theme, Murdoch Children's Research Institute, Victoria, Australia.

\section{(v) CORRESPONDING AUTHOR}

Dr Anita D’Aprano

Department of Paediatrics, University of Melbourne

Level 2 East, Royal Children's Hospital

50 Flemington Road, Parkville, Victoria, 3052, Australia

T: +61 393456959

E: anita.daprano@unimelb.edu.au

\section{(vi) ACKNOWLEDGEMENTS}

We would like to gratefully acknowledge the caregivers who participated in the study and the CaFHS staff who supported the study.

\section{(vii) CONFLICTS OF INTEREST}

The authors have no conflict of interest to declare.

\section{ABSTRACT}

This is the author manuscript accepted for publication and has undergone full peer review but has not been through the copyediting, typesetting, pagination and proofreading process, which may lead to differences between this version and the Version of Record. Please cite this article as doi: $10.1111 /$ jpc.15099

This article is protected by copyright. All rights reserved. 


\section{Background}

The ASQ-TRAK culturally adapted developmental screening tool is widely used in Australian Aboriginal communities. However, there has been limited exploration of the tool's acceptability to caregivers.

Aim

To determine the acceptability of the ASQ-TRAK developmental screening tool to caregivers of Aboriginal children in urban, regional and remote South Australia.

\section{Methods}

Caregivers of Aboriginal children completed a survey regarding acceptability of the ASQTRAK. A convenience sample of caregivers were invited to a telephone interview.

\section{Results}

Ninety-two caregivers completed the survey (96\% response). Acceptability (92\%) and caregiver satisfaction (73\%) were high. Families perceived the screen as easy to use and understand, strengths-based and providing valuable information about their child's development.

\section{Conclusions}

The ASQ-TRAK tool was highly acceptable to caregivers in Aboriginal communities in South Australia. The study highlights the importance of culturally safe practice and supports ASQTRAK implementation. Broader use and further evaluation of the ASQ-TRAK in Aboriginal communities needs consideration.

\section{KEY WORDS}

This article is protected by copyright. All rights reserved. 
Child development; Cross-cultural comparison; Culturally competent care; Indigenous health services

This article is protected by copyright. All rights reserved. 


\section{$\underline{\text { Introduction }}$}

Early childhood is increasingly recognised as a period of great developmental importance, with experiences of early childhood having effects on an individual throughout the lifespan ${ }^{(1)}$. Early child intervention has been demonstrated to mitigate some of the effects of early developmental difficulties ${ }^{(2,3)}$, however, this relies on early recognition.

Aboriginal and Torres Strait Islander people share a continuing legacy of resilience, strength and determination. However, their health and wellbeing continues to be impacted by dispossession, interruption of culture and intergenerational trauma ${ }^{(4)}$. While some gains have been made, Australian Aboriginal children still face greater adverse developmental challenges ${ }^{(5)}$ and are twice as likely as non-Indigenous children to be developmentally vulnerable at school entry ${ }^{(6)}$. While best practice recommends using structured developmental screening instruments ${ }^{(7)}$ until recently there have been no instruments validated for use with Aboriginal children and mainstream tools have been demonstrated to be poorly suited to this context ${ }^{(8)}$.

To address this gap, D'Aprano et al ${ }^{(9)}$ undertook a cross-cultural adaptation of the Ages and Stages Questionnaire, $3^{\text {rd }}$ edition (ASQ-3) developmental screening tool ${ }^{(10)}$. The ASQ-3 has documented acceptable psychometric properties ${ }^{(11)}$, and while it has acceptability across a number of different cultures and language groups, it is not validated for use in Indigenous contexts. The adapted ASQ-Talking about Raising Aboriginal Kids (ASQ-TRAK) has high face validity and is considered culturally acceptable by caregivers in communities where it was developed ${ }^{(9)}$. Further ASQ-TRAK research has shown acceptable psychometric properties, with sensitivity and specificity equivalent to the ASQ- $3^{(12)}$. Notably, the ASQ-TRAK is now

\footnotetext{
'Where the term 'Aboriginal' is used it refers to both Aboriginal and Torres Strait Islander people. Indigenous is retained when it is part of the title of a report, program or quotation.
}

This article is protected by copyright. All rights reserved. 
being adopted by both Aboriginal Community Controlled and mainstream health services across Australia ${ }^{25}$.

While these results are promising, it is unknown whether the results can be generalised to all Aboriginal communities across Australia. It must be acknowledged that Aboriginal people have great diversity of culture, language and lived experiences. While a greater proportion of Aboriginal people live remotely (21\%) as compared with non-Indigenous Australians (2\%), 79\% of Australia's Aboriginal population lives in urban and regional Australia ${ }^{(13)}$. Over 100 distinct Aboriginal languages are still spoken today with 10\% of Aboriginal people reporting that they speak an Aboriginal language at home ${ }^{(13)}$. This is increased in some regions with, for example, $60 \%$ of Aboriginal people in the Northern Territory speaking an Aboriginal language at home ${ }^{(13)}$. Thus, it cannot be assumed that the ASQ-TRAK will have the same acceptability outside the communities where it was designed.

The aim of this study was to investigate the acceptability of the ASQ-TRAK developmental screening tool among caregivers of Aboriginal children in urban, regional and remote South Australia.

\section{Methods}

\section{Study Design and Participants}

The study was undertaken as a partnership between the University of Melbourne and Women's and Children's Health Network (WCHN) Child and Family Health Service (CaFHS) in South Australia. A mixed methods approach was used for data collection and analysis comprising survey and participant interview.

Caregivers of Aboriginal children aged 0 to 4 years, who attended participating CaFHS sites and who were within the specified age ranges for the ASQ-TRAK questionnaires (Table 1) were eligible.

This article is protected by copyright. All rights reserved. 
Study sites were selected following consultation with CaFHS management, including the Aboriginal Cultural Consultant manager and clinical leads. The sites chosen were representative of the diversity of Aboriginal communities across SA. Two urban (Morphett Vale and Port Adelaide), one regional (Port Augusta) and six remote Anangu Pitjantjatjara Yankunytjatjara (APY) lands sites were included.

\section{Measures}

The ASQ-TRAK is the cross-cultural adaptation of the ASQ-3 developmental screening tool. The ASQ-3 consists of 21 questionnaires, each relating to a specific age interval, designed to be parent completed. Each questionnaire asks caregivers about their child's skills in five areas - communication, gross-motor, fine-motor, problem-solving and personal-social. An 'overall' section addresses medical, hearing or behaviour concerns and family history.

In contrast to the ASQ-3 the ASQ-TRAK: is shorter as it excludes the overall section; items are in plain English; is designed to be administered exclusively by interview; has only 7 available age-intervals; and items are accompanied by culturally relevant illustrations compiled in a standalone flipchart. The questionnaires are scored using ASQ-3 score sheets.

Staff participated in two-day classroom training followed by workplace practice, observed by the research team to ensure consistency of administration.

\section{Caregiver Survey}

Caregivers were surveyed about their ASQ-TRAK experience. The survey (appendix 1) was adapted from a practitioners' survey ${ }^{(20)}$. It included 9 questions, scored using a 5-point Likert rating scale, which addressed the ease, acceptability and overall satisfaction, and interest in future screens using the ASQ-TRAK. A further 3 questions invited free text comments.

This article is protected by copyright. All rights reserved. 


\section{Interview Guide}

A subgroup of caregivers participated in semi-structured telephone interviews to elicit their views on the ASQ-TRAK. An interview guide (appendix 2) was co-designed with CaFHS Aboriginal Cultural Consultants drawing on the study aims, particularly the caregiver experience.

\section{Procedure}

Data collection occurred from April 2017 to June 2018. Participants were invited by CaFHS nurses, Aboriginal Cultural Consultants or Early Childhood Intervention Consultants. The CaFHS staff-member provided written study information and obtained written informed consent. Staff administered the ASQ-TRAK at a time convenient for the family.

Caregiver Surveys were completed immediately after ASQ-TRAK administration and returned the same day. CaFHS staff completed the survey by interview for caregivers who had literacy issues or limited English. Researchers (KJ, YPC) collected the de-identified ASQTRAK questionnaires and caregiver surveys.

To obtain additional information, a convenience sample of caregivers were contacted via telephone, and following verbal consent, interviewed about their ASQ-TRAK experiences. An Aboriginal Clinical Lead with CaFHS, with no previous contact with the participants, conducted the interviews using the guide and supported by the research team (DJ). Interviews were audio recorded, transcribed and made available to participants.

\section{Analysis}

The research team analysed quantitative data using descriptive statistics. The 5-point Likert scale was collapsed into 3 groups for the purposes of analysis ("very/ extremely", "somewhat" and "not so/ not at all"). For the qualitative data, KJ, DP and MOK 
independently read each interview transcript and free text comments to identify preliminary themes. Using an iterative process of theme identification and hypothesis testing, all three authors compared initial themes with constant reference back to the original transcripts. This continued until consensus was reached that all data were captured within themes.

\section{Approvals}

Ethics approval was obtained from the Aboriginal Health Research Ethics Committee of South Australia (04-16-702), the Women's and Children's Health Network (HREC/16/WCH185) and the University of Melbourne (1646876). Approval was provided by the Executive Board of the APY Lands and research permits were obtained for these sites.

\section{$\underline{\text { Results }}$}

Of 96 caregivers who participated, 92 (96\%) returned surveys (note, some caregivers had more than one child who participated, hence the number of children totalling 99 in Table 2). This represented $95 \%$ of remote, $86 \%$ of regional and $100 \%$ of urban caregivers. Notably, $71 \%$ of surveys from the remote sites were only partially completed because staff assisting the families decided some questions were inappropriate. Characteristics of the children and staff who participated are detailed in Table 2.

Caregivers reported the ASQ-TRAK to be highly acceptable across all three regions, with 85 caregivers (92\%) finding the ASQ-TRAK to be "extremely/very acceptable". This was accompanied by high levels of satisfaction, with 67 (73\%) respondents reporting that they were "extremely/very satisfied" with the ASQ-TRAK (Table 3).

This article is protected by copyright. All rights reserved. 
Overall, 53 caregivers indicated they would be interested in future monitoring of their child's development using the ASQ-TRAK (58\%). In the regional and urban cohort $100 \%$ of participants indicated this, as opposed to $57 \%$ of the remote cohort.

\section{Interview data and free text comments}

Five urban and one regional caregiver participated in the telephone interview. No remote caregivers were interviewed as CaFHS services ceased in the area at that time (independent of the study). Forty-eight caregivers provided free text comments on the caregiver surveys; 24 urban, 9 regional and 23 remote caregivers. A number of characteristics of the ASQ-TRAK screen were highlighted in both the surveys and interviews that appear to have contributed to these very high levels of acceptability and satisfaction. Three overarching themes were identified: ease; information; and, strengths based approach and cultural relevance.

\section{Ease}

Caregivers consistently commented on how easy the ASQ-TRAK was; to read, understand, follow and do. Respondents commented that the illustrations and flipchart aided in understanding what was being asked of themselves and their child.

\section{Information}

Caregivers reported that using the tool improved their own knowledge of development and understanding of their child's developmental stage. This knowledge was valued whether the ASQ-TRAK revealed areas of delay, or whether development was on track:

"I learnt a lot of things that my daughter should be doing at that age that she wasn't so it helped me to get her the help that she needed." (parent, urban SA)

This article is protected by copyright. All rights reserved. 
"...it made me feel like my daughter was travelling the way she was supposed to and it gave me sense of mind that she was going well, doing well." (parent, urban SA)

\section{Strengths-based approach and cultural relevance}

Caregivers reported that they liked that the ASQ-TRAK focused on what the child could do and that questions were presented sensitively "so that there was no way you could be offended by things".

Caregivers reflected on positive feelings elicited during the screen. Some reported that they liked interacting with their child while doing the activities and observing the skills that they had mastered. Others reported that they enjoyed seeing their child joyful during the process of the ASQ-TRAK; laughing while playing for example.

Caregivers reported a sense of pride both during and following the screen; commenting for example that the ASQ-TRAK was:

"making me feel good about how I'm growing her up and how she is growing up." (parent, APY Lands)

Furthermore, caregivers reported a sense of pride in seeing Aboriginal people depicted in the illustrations. One respondent commented that the ASQ-TRAK felt:

"culturally sensitive and culturally right." (parent, urban SA)

\section{Discussion}

This study shows high levels of acceptability and satisfaction with the culturally adapted ASQ-TRAK developmental screening tool among urban, regional and remote Aboriginal 
families in South Australia. In particular, participants from all three cohorts reflected on the ease of use of the ASQ-TRAK and the high value placed on the information gained.

Our findings are in keeping with those of $D^{\prime} A p r a n o ~ e t ~ a l^{(9)}$ in which families spoke about the acceptability of the ASQ-TRAK, the value of the developmental information gained from the screen and the ease of administration. Participants in both studies also spoke to the cultural relevance of the tool. D'Aprano et al's cohort were families from the two remote communities where the adaptation process occurred. This study extends those findings with participating Aboriginal caregivers from urban and regional sites having similarly positive opinions about the ASQ-TRAK to remote dwelling caregivers.

Caregivers reported the ASQ-TRAK was respectful and educational, commenting on the value of gaining knowledge about their child through the screening process, reflecting the principles of respect, sharing and transparency. In providing a culturally appropriate tool, the ASQ-TRAK is taking an important step toward equity and social justice for Aboriginal Australians in this area. The importance of a strengths-based approach, together with community acceptance has been demonstrated to be crucial to the success of programs involving Aboriginal communities ${ }^{(14,15)}$. Caregivers commented that the tool led them to reflect both on the strengths of their child as well as the strengths of their own parenting. These comments are in keeping with a definition of a strengths-based approach simply being one which focuses on "the inherent strengths of the family." ${ }^{(16)}$ A strengths-based approach has been further described as being characterised by respect, sharing (of information, knowledge, resources and decision making), collaboration and partnership, social justice and transparency ${ }^{(16)}$.

This study demonstrated the additional benefit of building capacity within the Aboriginal Cultural Consultant workforce to conduct ASQ-TRAK assessments. This is relevant because inclusion of Aboriginal health staff has been shown to improve patient experience ${ }^{(17,18)}$ as 
well as improve community acceptance and new program success ${ }^{(14,19)}$. Promoting the Aboriginal Cultural Consultant's role in developmental monitoring with the ASQ-TRAK is an important strategy that supports the delivery of culturally safe services.

While acceptance and satisfaction in all groups was high, just over half of remote dwelling families expressed interest in ongoing monitoring of their child's development using the ASQ-TRAK as compared with all families from regional and urban sites. This may indicate that engagement was not as high within the remote group. However, this was an unexpected result, as prior work exploring practitioners' perceptions of the ASQ-TRAK in similar settings, found that staff rated the ASQ-TRAK to be significantly more engaging than the ASQ-3 for Aboriginal families ${ }^{(20)}$. A relevant factor that might explain this difference in our study is that while Aboriginal Cultural Consultants administered the majority of ASQTRAK questionnaires in urban and regional centres this did not occur in the remote sites. In these sites non-Aboriginal outreach child health nurses, not from the community, were responsible for administering the ASQ-TRAK. As described above, the presence of Aboriginal workers is an important way to achieve culturally safe care and the lack of this workforce has previously been identified as a barrier to engagement ${ }^{(19)}$. Another likely factor is the lack of interpreters in the remote sites, where only a small proportion of people speak English in the home ${ }^{(21)}$.

It is noteworthy that the majority of caregiver surveys (71\%) from the remote sites were only partially completed. This was largely due to omission of question 6 by study personnel, who administered the survey by interview, as it was deemed "too busy" and inappropriate for this population. While this may have limited the information gained from the remote sites, the attempted simplification may also have resulted in a greater overall response rate by improving the survey accessibility. Questions 7 and 8 also had lower response rates where the survey was administered by interview. The exclusion of these questions may have been due to difficulty translating the question. It is also possible that caregivers were 
reluctant to answer questions negatively when the survey was being administered by the staff member who administered the ASQ-TRAK, resulting in the question being omitted. The feedback from this cohort was further limited because CaFHS had withdrawn from the area prior to the interviews being conducted.

This study had limitations, as discussed. However addressing the lack of Aboriginal health professionals and interpreters in the remote settings was beyond the scope of the study. While the caregiver survey was administered by interview with remote families, this was not uniform and questions were omitted inconsistently. Furthermore, most caregiver surveys were administered by the CaFHS staff administering the ASQ-TRAK. This may have introduced bias, influencing caregivers to respond more positively ${ }^{(22)}$. Future studies could consider utilising a trusted interviewer who was not involved in administering the ASQ-

TRAK, which would be more aligned with culturally appropriate methods ${ }^{(23)}$. Consideration also needs to be given to the use and further evaluation of the ASQ-TRAK in Aboriginal communities more broadly.

\section{Conclusion}

This is the first study to explore urban and regional caregivers' perceptions of the ASQ-TRAK developmental screening tool and demonstrates high acceptability with Aboriginal families in SA. Families perceived the screen as easy to use and understand, being strengths-based and providing valuable information about their child's development. In addition, this study highlighted the importance of ensuring ASQ-TRAK administration is culturally safe. Including local Aboriginal staff in the process, ensuring non-Aboriginal staff who are involved are trusted practitioners, and availability of appropriate training are all essential strategies that support this ${ }^{(24)}$. Our findings support the use of the ASQ-TRAK and we recommend implementation across SA Aboriginal communities. Further expansion should occur in close consultation with participating communities at all stages of development, with translation of the tool into local language where possible. Universal developmental monitoring services 
need to be inclusive and accessible to ensure Aboriginal children with additional needs are not neglected.

This article is protected by copyright. All rights reserved. 


\section{References}

1. World Health Organization. Closing the gap in a generation: health equity through action on the social determinants of health. Final Report of the Commission on Social Determinants of Health. Geneva: World Health Organization; 2008.

2. RACP. Early intervention for children with developmental disabilities. 2013.

3. World Health Organization Department of Child and Adolescent Health and Development. A critical link: Interventions for physical growth and psychological development. World Health Organization; 19991999.

4. Department of Health. National Framework for Health Services for Aboriginal and Torres Strait Islander Children and Families,. In: Department of Health, editor. Canberra: Australian Government,; 2016.

5. Australian Institute of Health and Welfare. The health and welfare of Australia's Aboriginal and Torres Strait Islander peoples 2015. Canberra: AIHW2015.

6. Australian Early Development Census. (2015). National report. A Snapshot of Early Childhood Development in Australia. Retrieved from:

https://www.aedc.gov.au/resources/detail/2015-aedc-national-report.

7. Guevara JP, Gerdes M, Localio R, Huang YV, Pinto-Martin J, Minkovitz CS, et al. Effectiveness of developmental screening in an urban setting. Pediatrics. 2013;131(1):30-7.

8. D'Aprano A, Carapetis J, Andrews R. Trial of a developmental screening tool in remote Australian Aboriginal communities: a cautionary tale. Journal of Paediatrics and Child Health. 2011;47(1-2):12-7.

9. D'Aprano A, Silburn S, Johnston V, Robinson G, Oberklaid F, Squires J. Adaptation of the Ages and Stages Questionnaire for Remote Aboriginal Australia. Qual Health Res. 2016;26(5):613-25.

10. Squires J, Twombly E, Bricker D, Potter L. Ages and stages questionnaires user's guide 3rd ed. Baltimore, MD: Paul H Brookes Publishing Co; 2009.

11. Squires J, Bricker D, Potter L. Revision of a parent-completed development screening tool: Ages and Stages Questionnaires. J Pediatr Psychol. 1997;22(3):313-28.

12. Simpson S, D'Aprano A, Tayler C, Toon Khoo S, Highfold R. Validation of a culturally adapted developmental screening tool for Australian Aboriginal children: Early findings and next steps. Early Hum Dev. 2016;103:91-5.

13. Australian Bureau of Statistics. Estimates of Aboriginal and Torres Strait Islander Australians, June 20162016 [Available from:

https://www.abs.gov.au/AUSSTATS/abs@.nsf/DetailsPage/3238.0.55.001June\%202016?Op enDocument. 
14. Bowes J, Grace R. Review of early childhood parenting, education and health intervention programs for Indigenous children and families in Australia. Canberra: AIHW; 2014.

15. Herceg A. Improving health in Aboriginal and Torres Strait Islander mothers, babies and young children: a literature review. In: Department of Health and Ageing Healthy for Life program, editor. Canberra, ACT: Department of Health and Ageing Healthy for Life program; 2006.

16. Fenton A, Walsh K, Wong S, Cumming T. Using Strengths-Based Approaches in Early Years Practice and Research. International Journal of Early Childhood. 2015;47(1):27-52.

17. Josif CM, Kruske S, Kildea SV, Barclay LM. The quality of health services provided to remote dwelling aboriginal infants in the top end of northern Australia following health system changes: a qualitative analysis. BMC pediatrics. 2017;17(1):93.

18. Gwynne K, Lincoln M. Developing the rural health workforce to improve Australian Aboriginal and Torres Strait Islander health outcomes: a systematic review. Aust Health Rev. 2017;41(2):234-8.

19. Osborne K, Baum F, Brown L. What works? A review of actions addressing the social and economic determinants of Indigenous health. Canberra: AIHW; 2013.

20. D’Aprano A, Johnston H, Jarman R, Jeyaseelan D, Chan YP, Johansen K, et al. Practitioners' perceptions of the ASQ-TRAK developmental screening tool for use in Aboriginal children: A preliminary survey. Journal of Paediatrics and Child Health. 2020;56(1):94-101.

21. Australian Bureau of Statistics. 2016 Census QuickStats APY lands 2016 [Available from:

https://quickstats.censusdata.abs.gov.au/census_services/getproduct/census/2016/quickst at/406021138.

22. Bowling A. Mode of questionnaire administration can have serious effects on data quality. Journal of public health. 2005;27(3):281-91.

23. Laycock A, with Walker D, Harrison N, Brands J. Researching Indigenous health: A practical guide for researchers. Melbourne: The Lowitja Institute; 2011.

24. D'Aprano A, Silburn S, Johnston V, Oberklaid F, Tayler C. Culturally Appropriate Training for Remote Australian Aboriginal Health Workers: Evaluation of an Early Child Development Training Intervention. Journal of developmental and behavioral pediatrics. 2015;36(7):503-11.

25. Government of Western Australia Child and Adolescent Health Service. Ages and Stages Questionnaires; 2017 [retrieved 19 June 2020]. Available from: https://www.cahs.health.wa.gov.au/-/media/HSPs/CAHS/Documents/CommunityHealth/CHM/Ages-and-Stages-Questionnaires-ASQ.pdf?thn=0. 


\section{(i) TITLE}

\section{Acceptability of the culturally adapted ASQ-TRAK developmental screening tool to caregivers of Aboriginal children}

\section{(ii) TYPE OF MANUSCRIPT}

Original Article

\section{(iii) AUTHORS}

Kimberly Johansen ${ }^{1}$

Deepa Jeyaseelan ${ }^{1,2}$

Yee Pei Chan ${ }^{1}$

Samantha Simpson ${ }^{3}$

Maree O'Keefe 2,4

Anita D’Aprano ${ }^{3,5,6}$

\section{(iv) INSTITUTIONS}

1 Women's and Children's Health Network, Adelaide, South Australia, Australia.

2 Child Development Unit, Women's and Children's Health Network, Adelaide, South Australia, Australia.

3 Melbourne Graduate School of Education, University of Melbourne, Victoria, Australia.

4 Faculty of Health and Medical Sciences, University of Adelaide, South Australia, Australia.

5 Department of Paediatrics, University of Melbourne, Victoria, Australia.

6 Population Health Theme, Murdoch Children's Research Institute, Victoria, Australia.

\section{(v) CORRESPONDING AUTHOR}

Dr Anita D'Aprano

Department of Paediatrics, University of Melbourne

Level 2 East, Royal Children's Hospital

50 Flemington Road, Parkville, Victoria, 3052, Australia

T: +61393456959

E: anita.daprano@unimelb.edu.au

\section{(vi) ACKNOWLEDGEMENTS}

We would like to gratefully acknowledge the caregivers who participated in the study and the CaFHS staff who supported the study.

(vii) CONFLICTS OF INTEREST

The authors have no conflict of interest to declare. 
Table 1. Inclusion criteria as per ASQ-TRAK ${ }^{+}$age interval ASQ-TRAK

questionnaire

\begin{tabular}{ccc}
\hline 2 month & 1 month 0 days & 2 months 30 days \\
\hline 6 month & 5 months 30 days & 6 months 30 days \\
\hline 12 month & 11 months 0 days & 12 months 30 days \\
\hline 18 month & 17 months 0 days & 18 months 30 days \\
\hline 24 month & 23 months 0 days & 38 months 30 days \\
\hline 36 month & 34 months 16 days & 38 months 30 days \\
\hline 48 month & 45 months 0 days & 50 months 30 days
\end{tabular}

${ }^{+}$ASQ-TRAK - Ages and Stages Questionnaire-Talking about Raising Aboriginal Kids 
Table 2. Characteristics of children and staff

\begin{tabular}{|c|c|c|c|}
\hline & $\begin{array}{l}\text { Remote } \\
n=42(\%)\end{array}$ & $\begin{array}{l}\text { Regional } \\
n=14(\%)\end{array}$ & $\begin{array}{c}\text { Urban } \\
n=43(\%)\end{array}$ \\
\hline \multicolumn{4}{|l|}{ Children } \\
\hline Gender - Male & $20(48)$ & $9(64)$ & $23(53)$ \\
\hline Age range (months) & $3.6-48.6$ & $6.2-48.6$ & $1.2-49.9$ \\
\hline \multicolumn{4}{|c|}{ ASQ-TRAK $^{\dagger}$ questionnaire used } \\
\hline 2 month & $1 \quad(2)$ & 0 & $17(39)$ \\
\hline 6 month & $\begin{array}{ll}5 & (12)\end{array}$ & $7(50)$ & $\begin{array}{ll}8 & (19)\end{array}$ \\
\hline 12 month & $11(26)$ & $5(36)$ & $5 \quad(12)$ \\
\hline 18 month & $7 \quad(17)$ & 0 & $\begin{array}{ll}6 & (14)\end{array}$ \\
\hline 24 month & $5 \quad(12)$ & 0 & 4 (9) \\
\hline 36 month & $12(29)$ & $1(7)$ & $1(2)$ \\
\hline 48 month & 1 (2) & $1(7)$ & $2(5)$ \\
\hline
\end{tabular}

Staff member administering the ASQ-TRAK

\begin{tabular}{|c|c|c|c|}
\hline $\mathrm{ACC}^{\ddagger}$ only & 0 & $12(86)$ & $29(67)$ \\
\hline Nurse only & $42(100)$ & 0 & $14(33)$ \\
\hline $\mathrm{EClC}^{\S}$ only & 0 & 0 & 0 \\
\hline Combined & 0 & $2(14)$ & 0 \\
\hline
\end{tabular}

${ }^{\dagger}$ ASQ-TRAK - Ages and Stages Questionnaire-Talking about Raising Aboriginal Kids

${ }^{\ddagger} A C C$ - Aboriginal Cultural Consultant, ${ }^{\S} \mathrm{ECIC}$ - Early Childhood Intervention Consultant

This article is protected by copyright. All rights reserved. 
Table 3. Survey results

\begin{tabular}{|c|c|c|c|c|}
\hline Questions & $\mathrm{n}^{+}(\%)$ & $\mathrm{n}^{+}(\%)$ & $\mathrm{n}^{+}(\%)$ & $\mathrm{n}^{\ddagger}(\%)$ \\
\hline & Less than 20 mins & $20-45$ mins & More than 45 mins & $\begin{array}{c}\text { Total } \\
\text { responses }\end{array}$ \\
\hline Q 2. How long did it take you & $26(30)$ & $58(66)$ & $4(5)$ & $88(96)$ \\
\hline & Extremely/very & Somewhat & Not so/not at all & \\
\hline $\begin{array}{l}\text { Q 4. How easy were questions } \\
\text { to understand }\end{array}$ & $84(96)$ & $4(5)$ & 0 & $88(96)$ \\
\hline $\begin{array}{l}\text { Q 5. How acceptable is the } \\
\text { ASQ-TRAK }\end{array}$ & $85(99)$ & $1(1)$ & 0 & $86(93)$ \\
\hline $\begin{array}{l}\text { Q 7. Overall how satisfied are } \\
\text { you with the screening tool }\end{array}$ & $67(96)$ & $3(4)$ & 0 & $70(76)$ \\
\hline $\begin{array}{l}\text { Q 6. Do you think the ASQ- } \\
\text { TRAK is: }\end{array}$ & $\begin{array}{c}\text { Strongly } \\
\text { agree/agree }\end{array}$ & $\begin{array}{l}\text { Neither } \\
\text { agree or } \\
\text { disagree }\end{array}$ & $\begin{array}{l}\text { Disagree/strongly } \\
\text { disagree }\end{array}$ & \\
\hline - educational & $54(96)$ & 0 & $2(4)$ & $56(61)$ \\
\hline - $\quad$ culturally relevant & $48(92)$ & $3(6)$ & $1(2)$ & $52(57)$ \\
\hline - $\quad$ respectful & $53(98)$ & $1(2)$ & 0 & 54 (59) \\
\hline - $\quad$ acceptable & $53(98)$ & $1(2)$ & 0 & $54(59)$ \\
\hline - fun & $47(90)$ & $4(8)$ & $1(2)$ & $52(57)$ \\
\hline - $\quad$ interesting & $53(95)$ & $3(5)$ & 0 & $56(61)$ \\
\hline - $\quad$ practical & $50(98)$ & $1(2)$ & 0 & $51(55)$ \\
\hline - $\quad$ too detailed & $9(15)$ & $10(17)$ & $41(68)$ & $60(65)$ \\
\hline - unnecessary & $3(6)$ & $7(15)$ & $38(79)$ & $48(52)$ \\
\hline - $\quad$ too time consuming & $3(6)$ & $6(12)$ & $43(83)$ & $52(57)$ \\
\hline
\end{tabular}

\footnotetext{
${ }^{\dagger}$ Represents the number of responses received for each question and as a percentage of the total number of study participants who answered this question.

${ }^{\ddagger}$ Represents the total number of responses received for each question and as a percentage of the total number of study participants overall.

${ }^{\S}$ ASQ-TRAK - Ages and Stages Questionnaire-Talking about Raising Aboriginal Kids
} 


\section{University Library}

\section{- M I I N E R VA \\ A gateway to Melbourne's research publications}

Minerva Access is the Institutional Repository of The University of Melbourne

Author/s:

Johansen, K;Jeyaseelan, D;Chan, YP;Simpson, S;O'Keefe, M;D'Aprano, A

Title:

Acceptability of the culturally adapted ASQ-TRAK developmental screening tool to caregivers of Aboriginal children

Date:

2020-08-20

Citation:

Johansen, K., Jeyaseelan, D., Chan, Y. P., Simpson, S., O'Keefe, M. \& D'Aprano, A. (2020). Acceptability of the culturally adapted ASQ-TRAK developmental screening tool to caregivers of Aboriginal children. JOURNAL OF PAEDIATRICS AND CHILD HEALTH, 56 (12), pp.1946-1951. https://doi.org/10.1111/jpc. 15099.

Persistent Link:

http://hdl.handle.net/11343/276172 